\title{
Incorporation of complexation into coamorphous system dramatically enhances dissolution and eliminates gelation of amorphous lurasidone hydrochloride
}

Weili Heng, ${ }^{\# \dagger}$ Meiling Su, ${ }^{\#, \dagger}$ Hao Cheng, ${ }^{\star}$ Peiya Shen, ${ }^{\star}$ Shujun Liang, ${ }^{\dagger}$ Linghe Zhang, ${ }^{\S}$

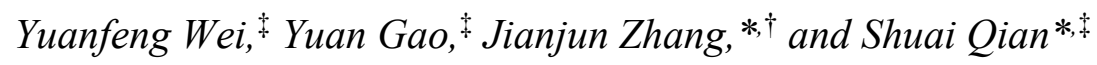

† School of Pharmacy, China Pharmaceutical University, Nanjing, 211198, P.R., China

$\$$ School of Traditional Chinese Pharmacy, China Pharmaceutical University, Nanjing, 211198, P.R., China

$\S$ Department of Chemistry, Smith College, Northampton, MA 01063, United States of America 


\section{Supporting Information}

\section{Polarized light microscope (PLM)}

PLM (DMLP, Leica Microsystems Wetzlar GmbH, Germany) was also used to distinguish amorphous material from crystalline solid. A small amount of samples was placed on the glass slide and dispersed adequately by little liquid paraffin. The morphology of samples was observed under PLM with $25 \times 10$ times magnification.



(a)

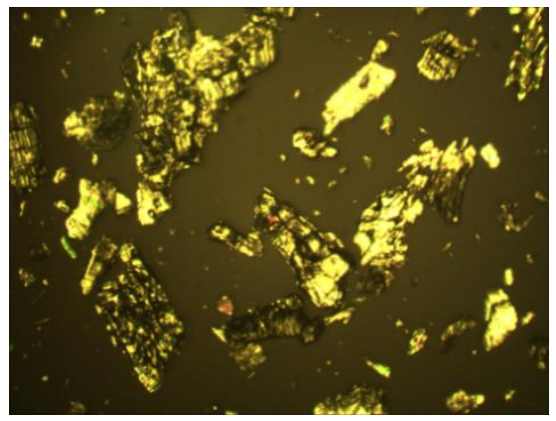

(c)

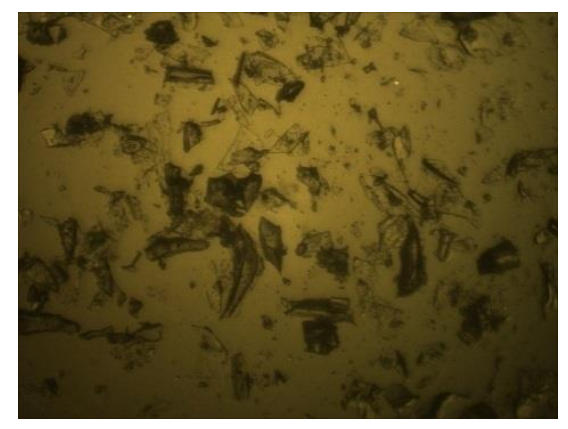

(b)

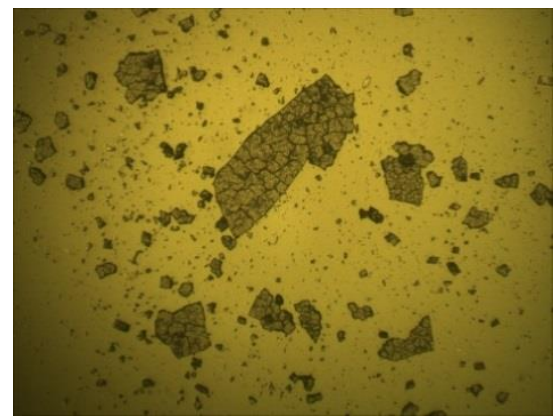

(d)

Figure S1. PLM photographs of (a) crystalline LH, (b) amorphous LH, (c) crystalline CYS, and (d) coamorphous LH-CYS 


\section{Supporting Information}

\section{Modulated Differential scanning calorimetry (mDSC)}

The mDSC thermograms of amorphous LH and coamorphous LH-CYS were obtained using Q2000 DSC (TA instruments, New Castle, USA). Routine calibration of the instrument was performed with an indium standard. Approximately $4 \mathrm{mg}$ of each sample was filled in an aluminum Tzero pan and sealed with a lid. The measurements were conducted from $-40 \sim 200$ ${ }^{\circ} \mathrm{C}$ at a heating rate of $2{ }^{\circ} \mathrm{C} / \mathrm{min}$ with an amplitude of $0.3{ }^{\circ} \mathrm{C}$ and a period of $60 \mathrm{~s}$. The mDSC data was analyzed using TA instruments Trios software (version 3.3.1). $\mathrm{T}_{\mathrm{g}}$ was determined from the reversing heat flow signal.

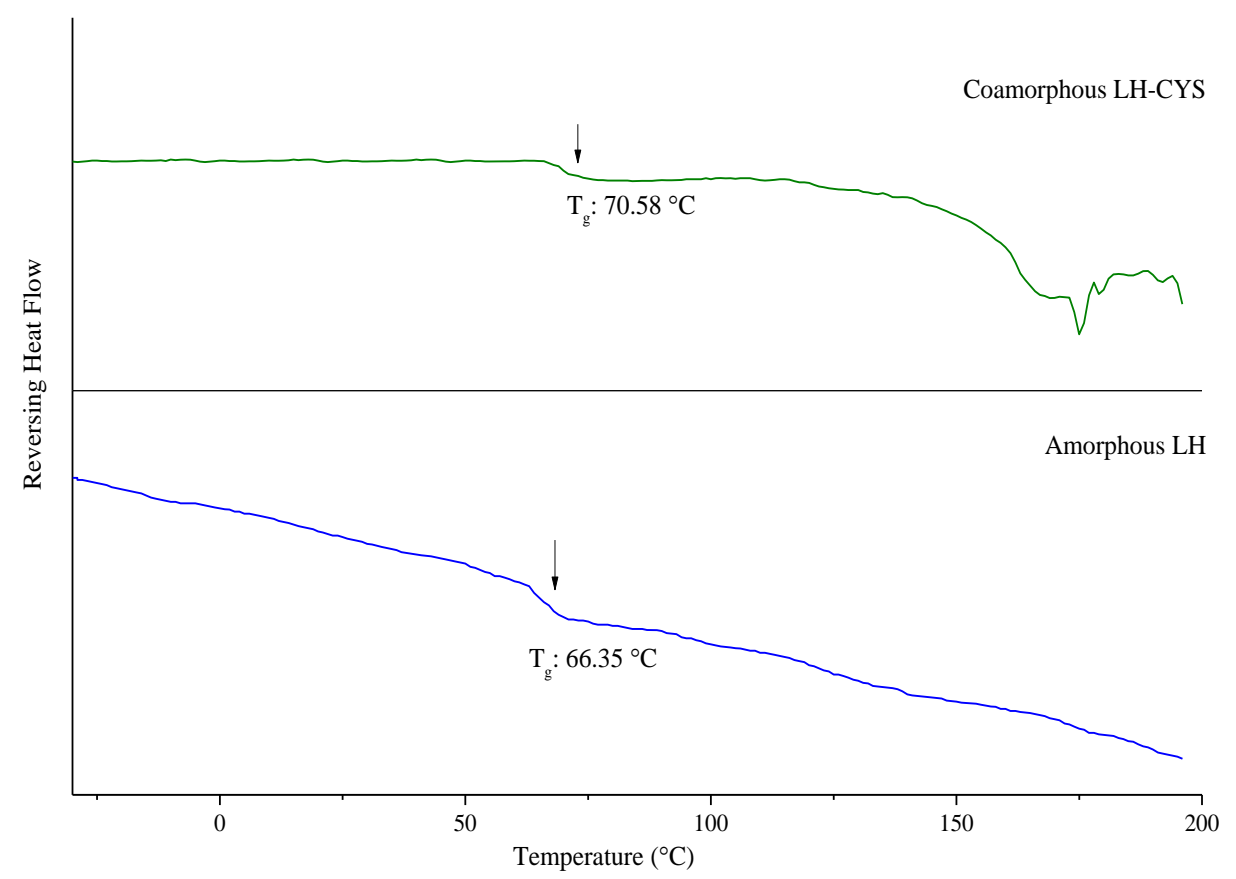

Figure S2. mDSC thermograms of amorphous LH and coamorphous LH-CYS 


\section{Supporting Information}

Figure S3. Proposed mechanism of fluorescence quenching, (A) Energy diagrams and the frontier orbital contribution of LH and CYS obtained from density functional theory (DFT) calculations at B3LYP/6-311++G(d,p) level using Gaussian 6.0 software. The energy gap between the highest occupied molecular orbital (HOMO) and lowest unoccupied molecular orbital (LUMO) was calculated to be $3.225 \mathrm{eV}$ for the complex LH-CYS; (B) The formation of ground-state complex in aqueous solution, and electron transfer from LH (electron donor) to CYS (electron acceptor) when LUMO of CYS $(-5.276 \mathrm{eV})$ is lower than LUMO of LH $(-3.850 \mathrm{eV}),{ }^{1}$ which would be responsible for the fluorescence quenching. ${ }^{2,3}$ Hydrogen bonding may lower the ionization potential of the donor and increase the electron affinity of the acceptor, thus facilitating the photoinduced electron transfer between the two moieties. ${ }^{3,4}$

A

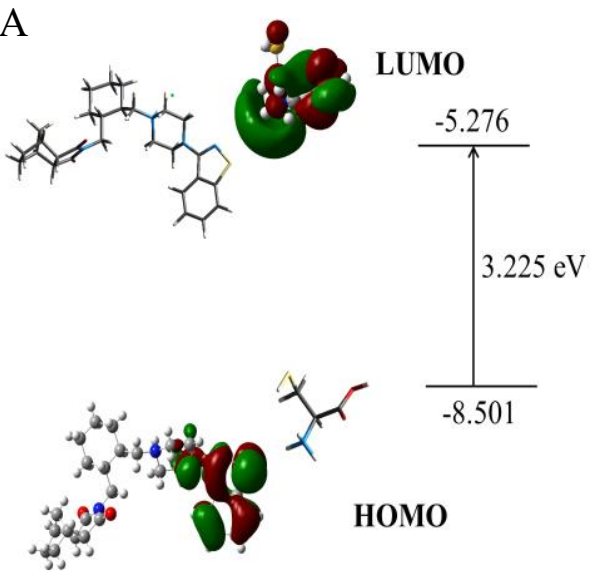

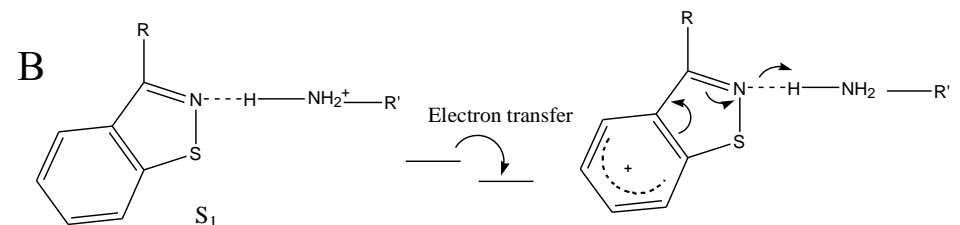

$\mathrm{S}_{1}$

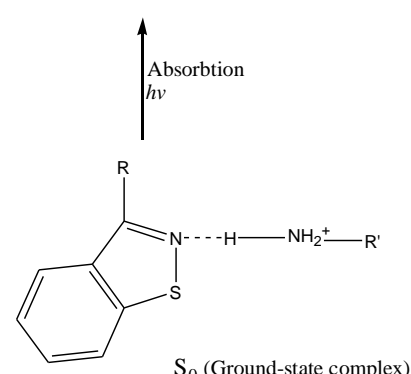

$\mathrm{S}_{0}$ (Ground-state complex)

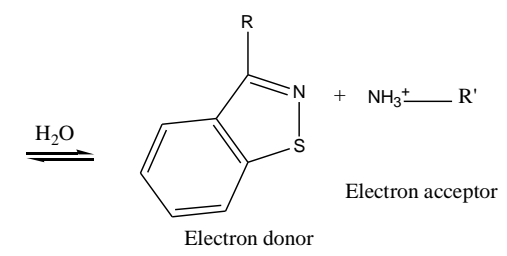


Figure S4. (A) Supersaturated dissolution profiles of coamorphous LH-CYS and physical mixture of crystalline LH and CYS in pH 3.8 PBS, and (B) PXRD patterns of collected solids at various time points during dissolution of the coamorphous system
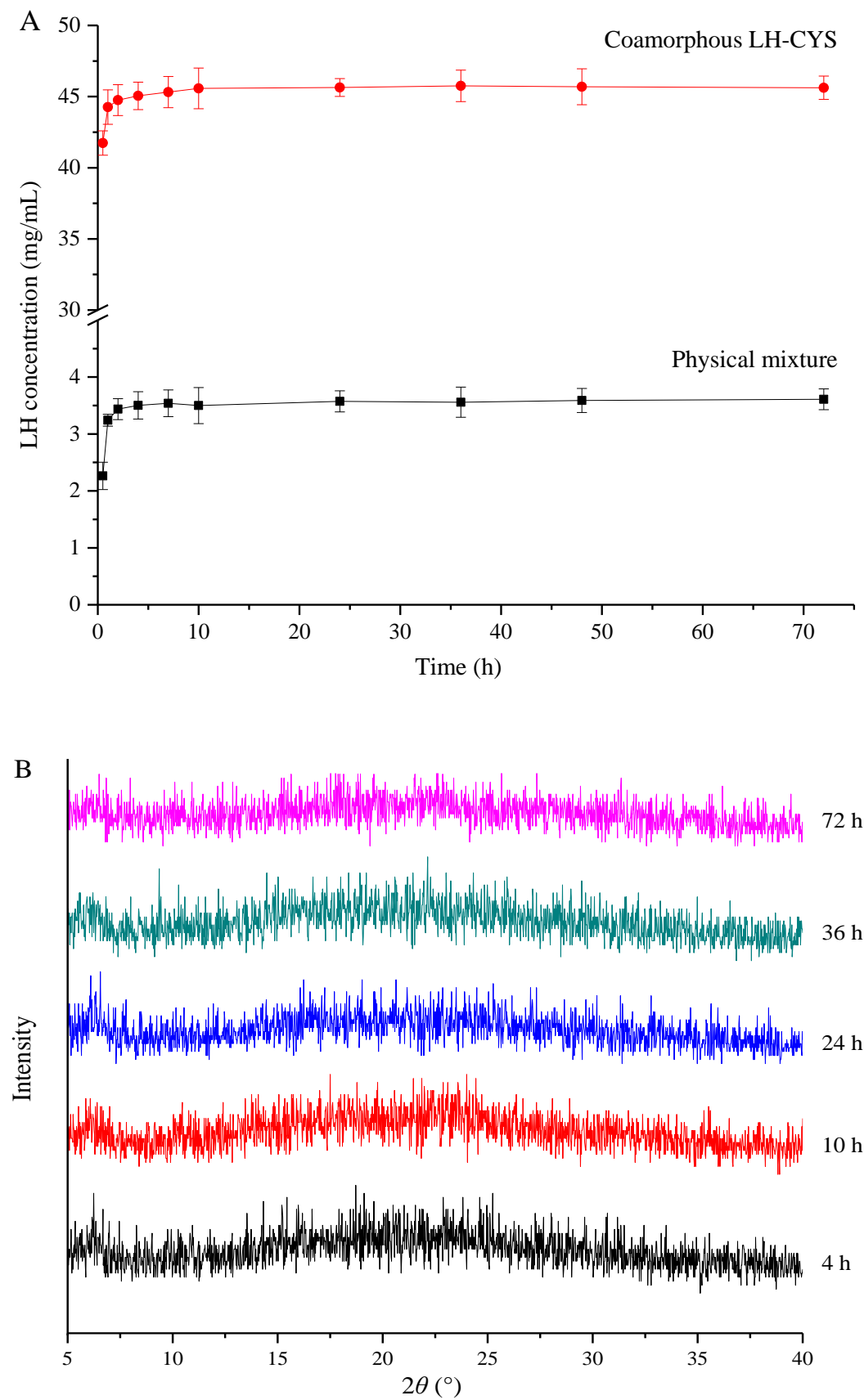
Figure S5. SEM images of (A) amorphous $\mathrm{LH}^{5}$ and (B) coamorphous LH-CYS before and after dissolution

A

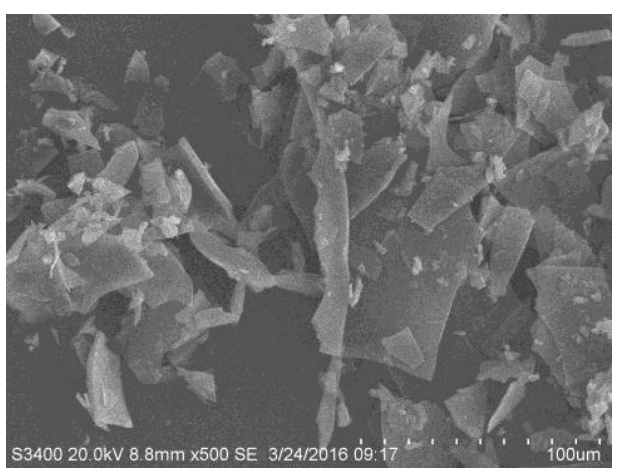

Before dissolution

B

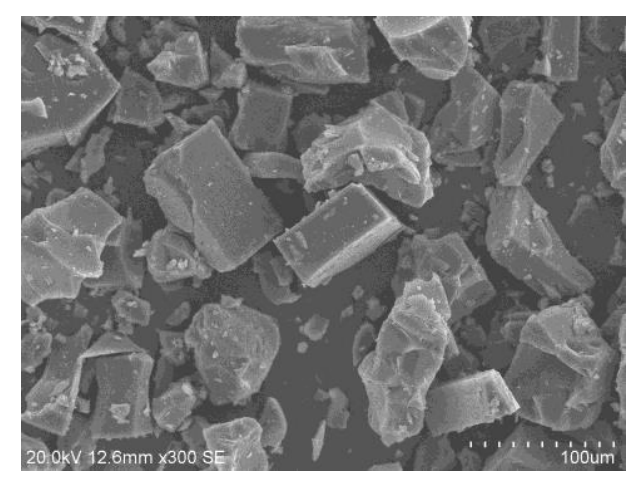

Before dissolution



After dissolution

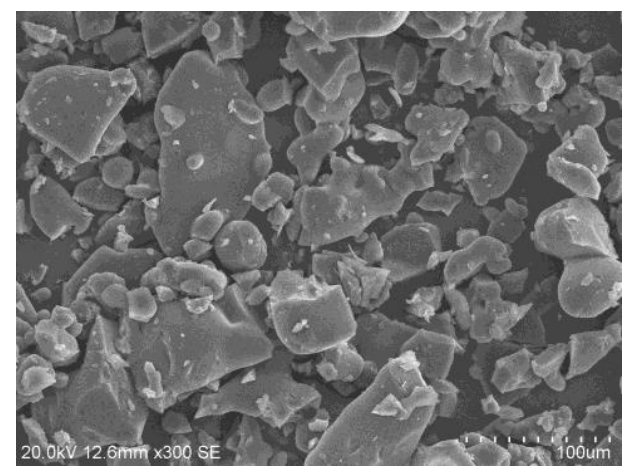

After dissolution 


\section{Physical stability}

Amorphous LH and coamorphous LH-CYS were exposed to $25^{\circ} \mathrm{C} / 60 \%$ RH environment (i.e. long-term storage condition) and $40{ }^{\circ} \mathrm{C} / 75 \% \mathrm{RH}$ (i.e. accelerated storage condition) in a constant temperature/humidity chamber (Shanghai Boxun Industry \& Commerce Co., Ltd., China). Samples were determined at predetermined time to investigate the physical and chemical stability of amorphous materials by PXRD, DSC and HPLC.

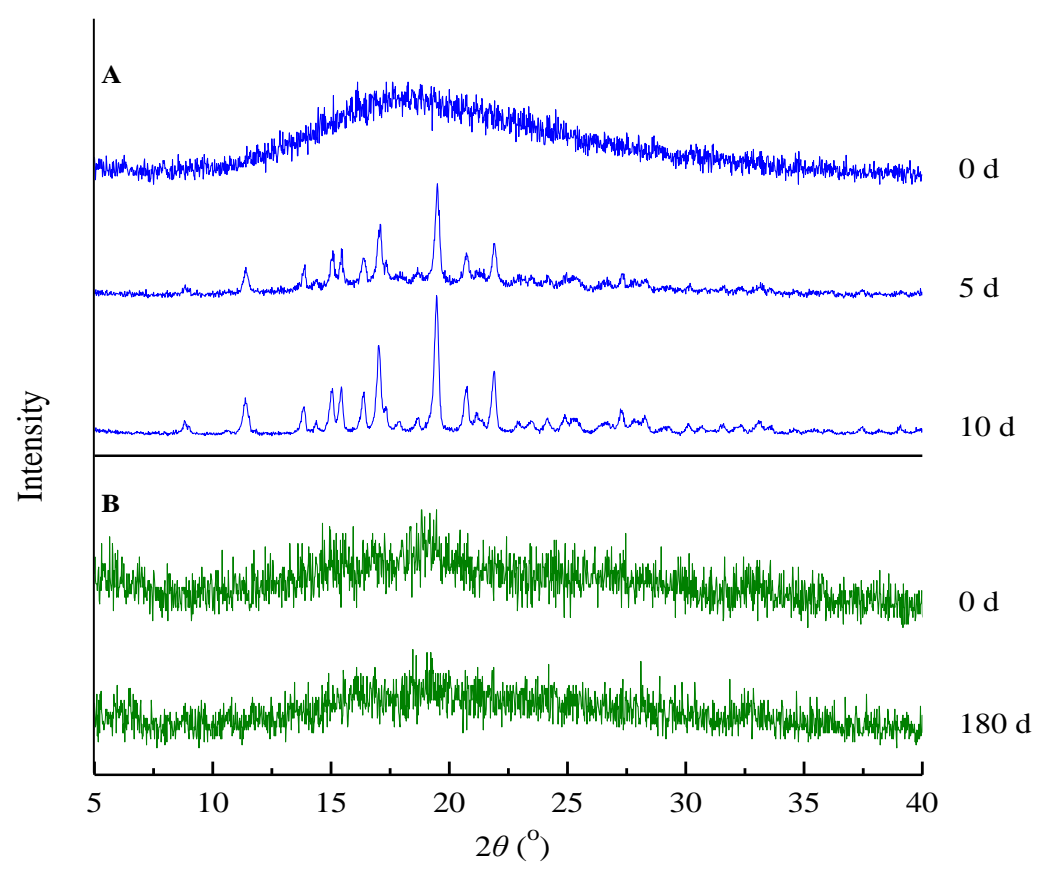

Figure S6. PXRD patterns of (A) amorphous LH and (B) coamorphous LH-CYS stored at 25 ${ }^{\circ} \mathrm{C} / 60 \% \mathrm{RH}$ over a specified period 


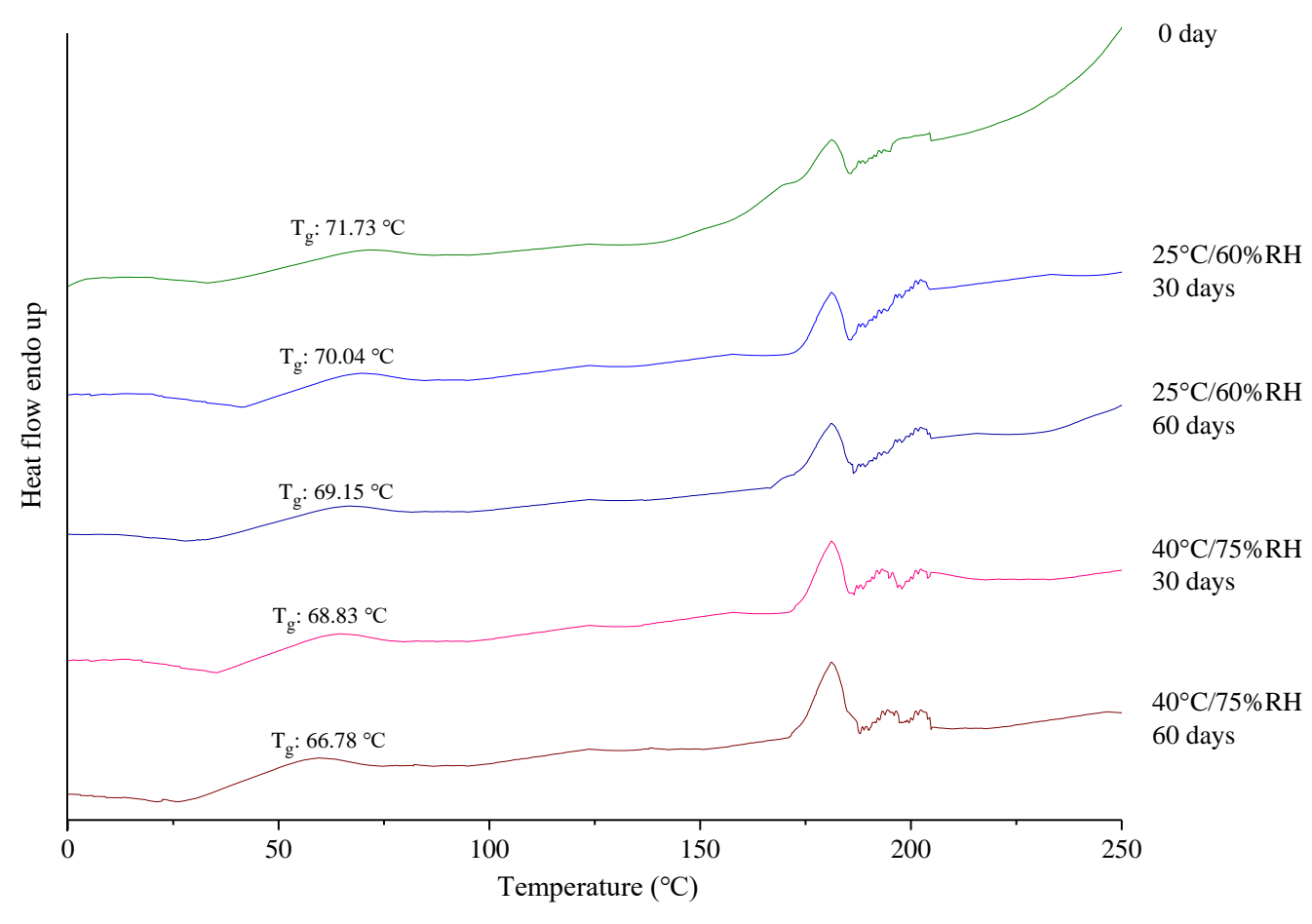

Figure S7. DSC curves of coamorphous LH-CYS collected at 30 and 60 days when exposed to $25{ }^{\circ} \mathrm{C} / 60 \% \mathrm{RH}$ and $40{ }^{\circ} \mathrm{C} / 75 \% \mathrm{RH}$ conditions

Table S1. LH content in coamorphous LH-CYS when exposed to various storage conditions

\begin{tabular}{cccc}
\hline \multirow{2}{*}{ Storage conditions } & \multicolumn{3}{c}{ LH content } \\
\cline { 2 - 4 } & $\mathbf{0}$ day & $\mathbf{3 0}$ days & $\mathbf{6 0}$ days \\
\hline $25^{\circ} \mathrm{C} / 60 \% \mathrm{RH}$ & $77.12 \pm 0.14 \%$ & $77.06 \pm 0.08 \%$ & $76.92 \pm 0.21 \%$ \\
$40^{\circ} \mathrm{C} / 75 \% \mathrm{RH}$ & & $76.95 \pm 0.16 \%$ & $77.04 \pm 0.27 \%$ \\
\hline
\end{tabular}




\section{Supporting Information}

\section{Dynamic Vapor Sorption (DVS)}

Dynamic vapor sorption of amorphous LH and coamorphous LH-CYS were performed at 25 ${ }^{\circ} \mathrm{C}$ using DVS Intrinsic (Surface Measurement Systems Ltd., London, UK). Samples were initially dried at relative humidity $(\mathrm{RH})<0.1 \%$. The $\mathrm{RH}$ was then increased from $0 \%$ to $98 \%$ (in $10 \%$ steps from $0 \%$ to $90 \%$, and one $8 \%$ step form $90 \%$ to $98 \%$ ), and then decreased in the opposite manner. For all RH steps, the "equilibrium" $\mathrm{d} m / \mathrm{d} t$ value was set at $0.002 \% / \mathrm{min}$. The minimum and maximum stage time were fixed to be 10 and $180 \mathrm{~min}$, respectively.



B
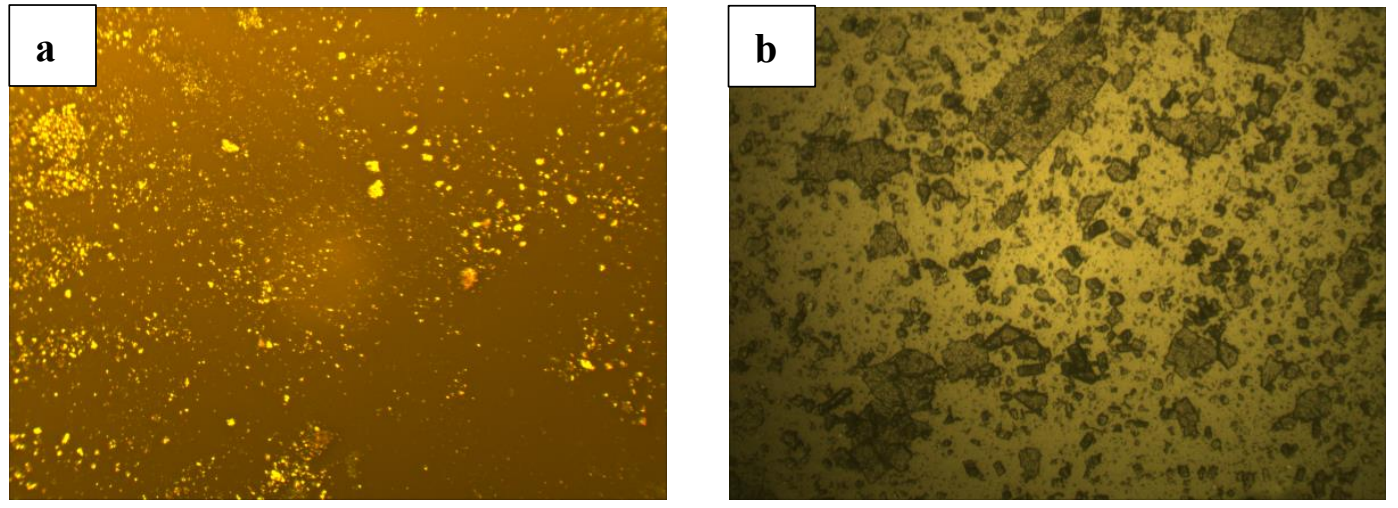

Figure S8. (A) Vapor sorption isotherms of amorphous LH and coamorphous LH-CYS at 25

${ }^{\circ} \mathrm{C}$; (B) PLM photographs of samples collected at the end of DVS determination for (a) amorphous LH and (b) coamorphous LH-CYS 


\section{Supporting Information}

\section{Recrystallization inhibition of amorphous LH by CYS}

Crystallization processes of amorphous LH in water (Figure S9A) and CYS solution (Figure S9B) were conducted by dropping $\sim 100 \mu \mathrm{L}$ of water or CYS solution $(6 \mathrm{mg} / \mathrm{mL})$ to amorphous LH powder via a needle on the glass slide. Photos were taken at various time points under PLM. Amorphous LH began to recrystallize with birefringence at $1 \mathrm{~min}$ and nearly completely transformed into its crystalline form at 4 min after adding water. However, when adding CYS aqueous solution to amorphous powder, the recrystallization of amorphous LH was significantly inhibited with birefringence initially occurring at $10 \mathrm{~min}$.

A

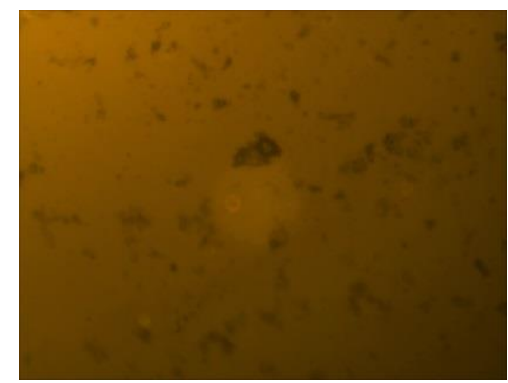

$0 \mathrm{~s}$

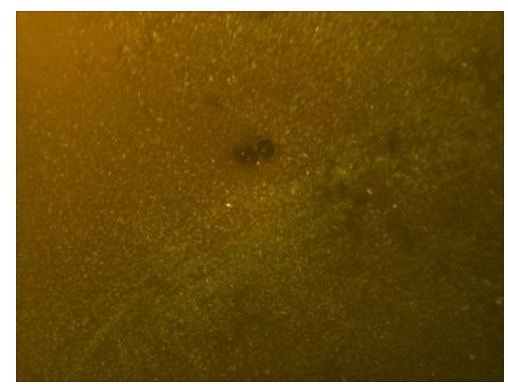

2 min

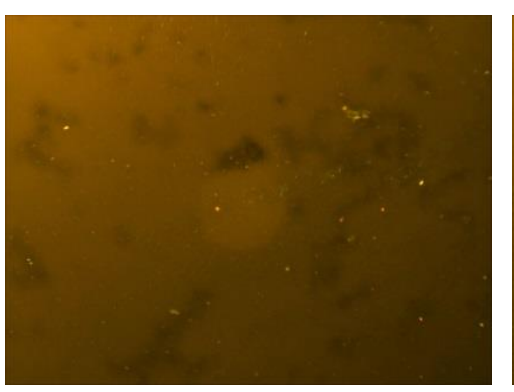

$1 \min$

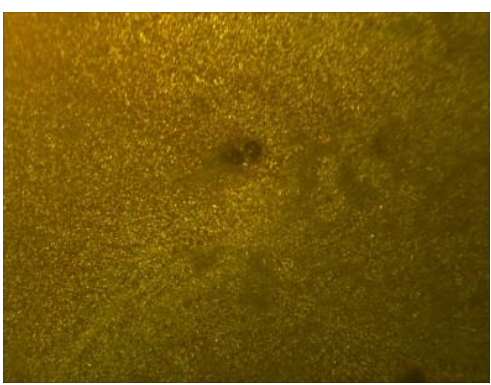

3 min

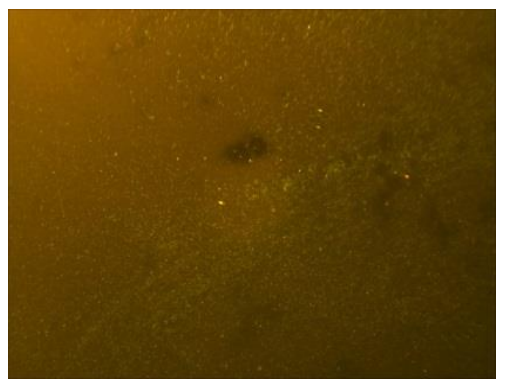

$1.5 \mathrm{~min}$

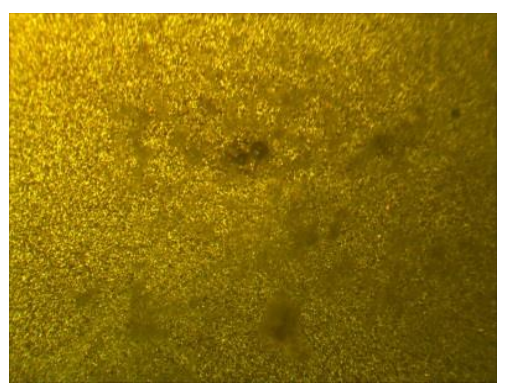

4 min 


\section{Supporting Information}

B

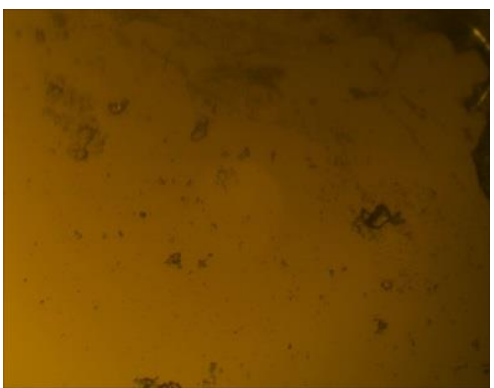

$0 \mathrm{~min}$

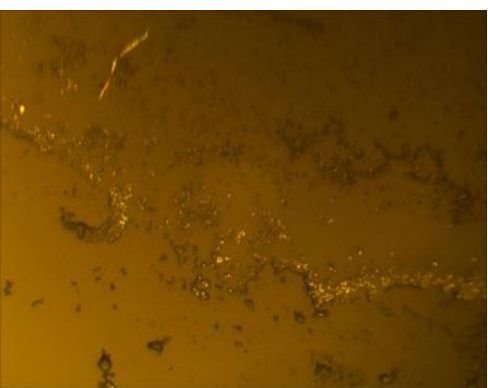

$20 \min$

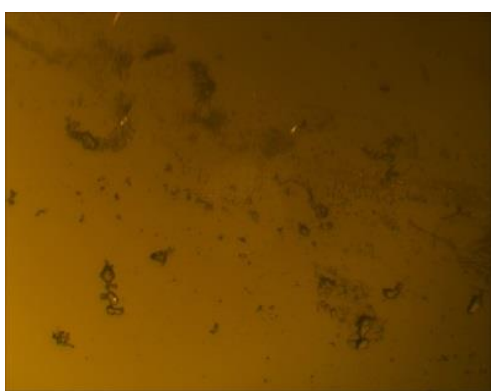

$5 \mathrm{~min}$

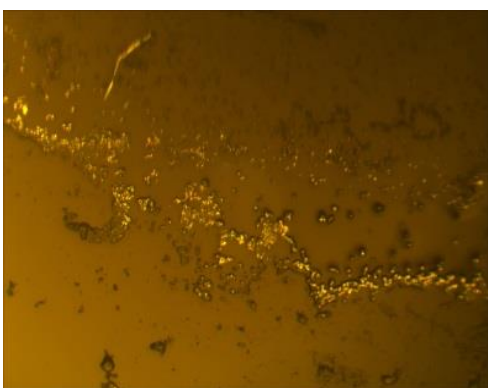

$40 \mathrm{~min}$

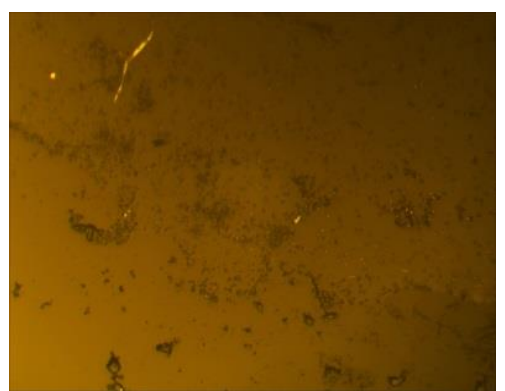

$10 \mathrm{~min}$

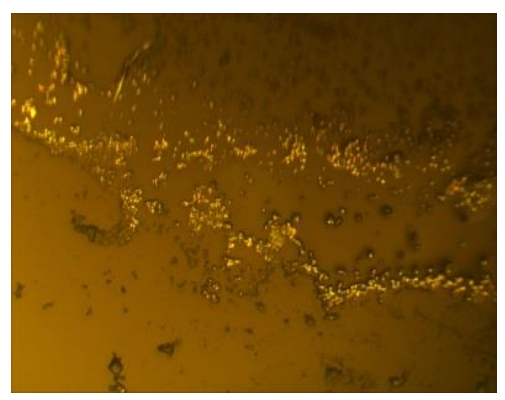

$60 \mathrm{~min}$

Figure S9. Observation on recrystallization of amorphous LH after adding (A) water or (B)

CYS aqueous solution to amorphous powder under PLM 


\section{Supporting Information}

Table S2. Resonance assignments of LH and CYS in ${ }^{13} \mathrm{C}$ NMR spectra in solid state and liquid state $\left(\mathrm{D}_{2} \mathrm{O}\right)$

\begin{tabular}{|c|c|c|c|}
\hline \multirow{2}{*}{ Compound } & \multirow{2}{*}{ Carbon Number } & \multicolumn{2}{|c|}{ Chemical shift (ppm) } \\
\hline & & Solid-state & Liquid-state \\
\hline \multirow{21}{*}{ LH } & 25,31 & 180.92 & 183.32 \\
\hline & 3 & 162.93 & 162.38 \\
\hline & 4 & 152.18 & 151.92 \\
\hline & \multirow{5}{*}{$5-9$} & 130.70 & 128.87 \\
\hline & & 128.48 & 126.86 \\
\hline & & 126.81 & 124.96 \\
\hline & & 123.40 & 123.68 \\
\hline & & 121.53 & 120.92 \\
\hline & 16 & 63.56 & 60.66 \\
\hline & 12,14 & 57.00 & 53.39 \\
\hline & 11,15 & 51.54 & 50.06 \\
\hline & 26,30 & 47.64 & 48.52 \\
\hline & 27,29 & 45.22 & 46.61 \\
\hline & 23 & 41.31 & 41.49 \\
\hline & 28 & 40.24 & 39.57 \\
\hline & 17 & 36.67 & 38.42 \\
\hline & 18 & 33.82 & 33.14 \\
\hline & 22 & 32.64 & 32.76 \\
\hline & 19 & 28.87 & 28.53 \\
\hline & 32,33 & 25.86 & 27.37 \\
\hline & 20,21 & 24.82 & 23.56 \\
\hline \multirow{3}{*}{ CYS } & 1 & 171.01 & 170.07 \\
\hline & 2 & 54.88 & 54.72 \\
\hline & 3 & 23.98 & 24.03 \\
\hline
\end{tabular}




\section{Supporting Information}

\section{References}

(1) Peng, H. L.; Callender, R. Mechanism for fluorescence quenching of tryptophan by oxamate and pyruvate: conjugation and solvation-induced photoinduced electron transfer. J. Phys. Chem. B 2018, 122, (25), 6483-6490.

(2) Doose, S.; Neuweiler, H.; Sauer, M. Fluorescence quenching by photoinduced electron transfer: a reporter for conformational dynamics of macromolecules. ChemPhysChem 2009, 10, (9-10), 1389-1398.

(3) Herbich, J.; Kijak, M.; Zielinska, A.; Thummel, R. P.; Waluk, J. Fluorescence quenching by pyridine and derivatives induced by intermolecular hydrogen bonding to pyrrole-containing heteroaromatics. J. Phys. Chem. A 2002, 106, (10), 2158-2163.

(4) Miyasaka, H.; Tabata, A.; Kamada, K.; Mataga, N. Femtosecond picosecond laser photolysis studies on the mechanisms of electron-transfer-induced by hydrogen-bonding interactions in nonpolar solutions: 1-aminopyrene pyridine systems. J. Am. Chem. Soc. 1993, 115, (16), 7335-7342.

(5) Heng, W.; Wei, Y.; Zhou, S.; Ma, D.; Gao, Y.; Zhang, J.; Qian, S. Effects of temperature and ionic strength of dissolution medium on the gelation of amorphous lurasidone hydrochloride. Pharm. Res. 2019, 36, (5), 72. 